\title{
Polyoxometalate (POM)-Layered Double Hydroxides (LDH) Composite Materials: Design and Catalytic Applications
}

\author{
Tengfei Li ${ }^{1}$, Haralampos N. Miras ${ }^{2, *}$ (D) and Yu-Fei Song ${ }^{1,3, *}$ \\ 1 State Key Laboratory of Chemical Resource Engineering, Beijing University of Chemical Technology, \\ Beijing 100029, China; 18810959180@163.com \\ 2 WestCHEM, School of Chemistry, the University of Glasgow, Glasgow G12 8QQ, UK \\ 3 Beijing Advanced Innovation Center for Soft Matter Science and Engineering, \\ Beijing University of Chemical Technology, Beijing 100029, China \\ * Correspondence: charalampos.moiras@glasgow.ac.uk (H.N.M.); songyf@mail.buct.edu.cn or \\ songyufei@hotmail.com (Y.-F.S.); Tel.: +44-(0)-141-330-4375 (H.N.M.); +86-10-6443-1832 (Y.-F.S.); \\ Fax: +86-10-6443-1832 (Y.-F.S.)
}

Academic Editor: Ivan V. Kozhevnikov

Received: 9 August 2017; Accepted: 24 August 2017; Published: 1 September 2017

\begin{abstract}
Layered double hydroxides (LDHs) are an important large class of two-dimensional (2D) anionic lamellar materials that possess flexible modular structure, facile exchangeability of inter-lamellar guest anions and uniform distribution of metal cations in the layer. Owing to the modular accessible gallery and unique inter-lamellar chemical environment, polyoxometalates (POMs) intercalated with LDHs has shown a vast array of physical properties with applications in environment, energy, catalysis, etc. Here we describe how polyoxometalate clusters can be used as building components for the construction of systems with important catalytic properties. This review article mainly focuses on the discussion of new synthetic approaches developed recently that allow the incorporation of the element of design in the construction of a fundamentally new class of materials with pre-defined functionalities in catalytic applications. Introducing the element of design and taking control over the finally observed functionality we demonstrate the unique opportunity for engineering materials with modular properties for specific catalytic applications.
\end{abstract}

Keywords: layered double hydroxides; polyoxometalates; intercalated materials

\section{Layered Double Hydroxides (LDHs)-Intro Background}

Layered double hydroxides (LDHs) or hydrotalcite-like compounds are a large family of two-dimensional (2D) anionic clay materials made up of positively charged brucite-like layers with an interlayer region containing charge compensating anions and solvation molecules, which can be represented by the general formula $\left[\mathrm{M}_{1-x}{ }^{\mathrm{II}} \mathrm{M}_{x} \mathrm{III}(\mathrm{OH})_{2}\right]^{x+}\left[\mathrm{A}_{x / n}\right]^{n-} \cdot \mathrm{mH}_{2} \mathrm{O}$ [1-4]. As shown in Figure 1, the $\mathrm{LDH}$ layers incorporate divalent $\mathrm{M}^{\mathrm{II}}$ (e.g., $\mathrm{Mg}^{\mathrm{II}}, \mathrm{Fe}^{\mathrm{II}}, \mathrm{Co}^{\mathrm{II}}, \mathrm{Cu}^{\mathrm{II}}, \mathrm{Ni}^{\mathrm{II}}$, or $\mathrm{Zn}^{\mathrm{II}}$ ) and trivalent $\mathrm{M}^{\mathrm{III}}$ metal cations (e.g., $\mathrm{Al}^{\mathrm{III}}, \mathrm{Cr}^{\mathrm{III}}, \mathrm{Ga}^{\mathrm{III}}, \mathrm{In}^{\mathrm{III}}, \mathrm{Mn}^{\mathrm{III}}$ or $\mathrm{Fe}^{\mathrm{III}}$ ), forming positively charged layers. $\mathrm{A}^{\mathrm{n}-}$ are mainly inorganic or organic anions (e.g., $\mathrm{CO}_{3}{ }^{2-}, \mathrm{Cl}^{-}, \mathrm{SO}_{4}{ }^{2-}, \mathrm{RCO}_{2}{ }^{-}$), where $x$ is the molar ratio of $\mathrm{M}^{\mathrm{II}} / \mathrm{M}^{\mathrm{III}}$ and generally in the range of $0.20-0.33$, which occupy the space between the layers compensating for the positive charge and inducing stability in the overall structure $[5,6]$. The $\mathrm{M}^{\mathrm{II}} / \mathrm{M}^{\mathrm{III}}$-based edge shared octahedra are used to construct 2D infinite sheets, whereas hydroxyl groups are organized on the vertices of the octahedra with the hydrogen atoms pointing toward the interlayer region, as a consequence forming a complex network of hydrogen bonds with the interlayer anions and water molecules [1,7-10]. LDH-based materials are very attractive systems due to their robust structure, 
wide range of compositions and flexible properties which can be finely modulated by suitable selection of metal cations, functional interlayer compensating anions, ratio of $\mathrm{M}^{\mathrm{II}} /\left(\mathrm{M}^{\mathrm{II}}+\mathrm{M}^{\mathrm{III}}\right)$, as well as the relative weak interlayer bonding. All the above physical and chemical properties render the LDH as exceptional candidates for the development of functional materials with versatile physical and chemical properties.

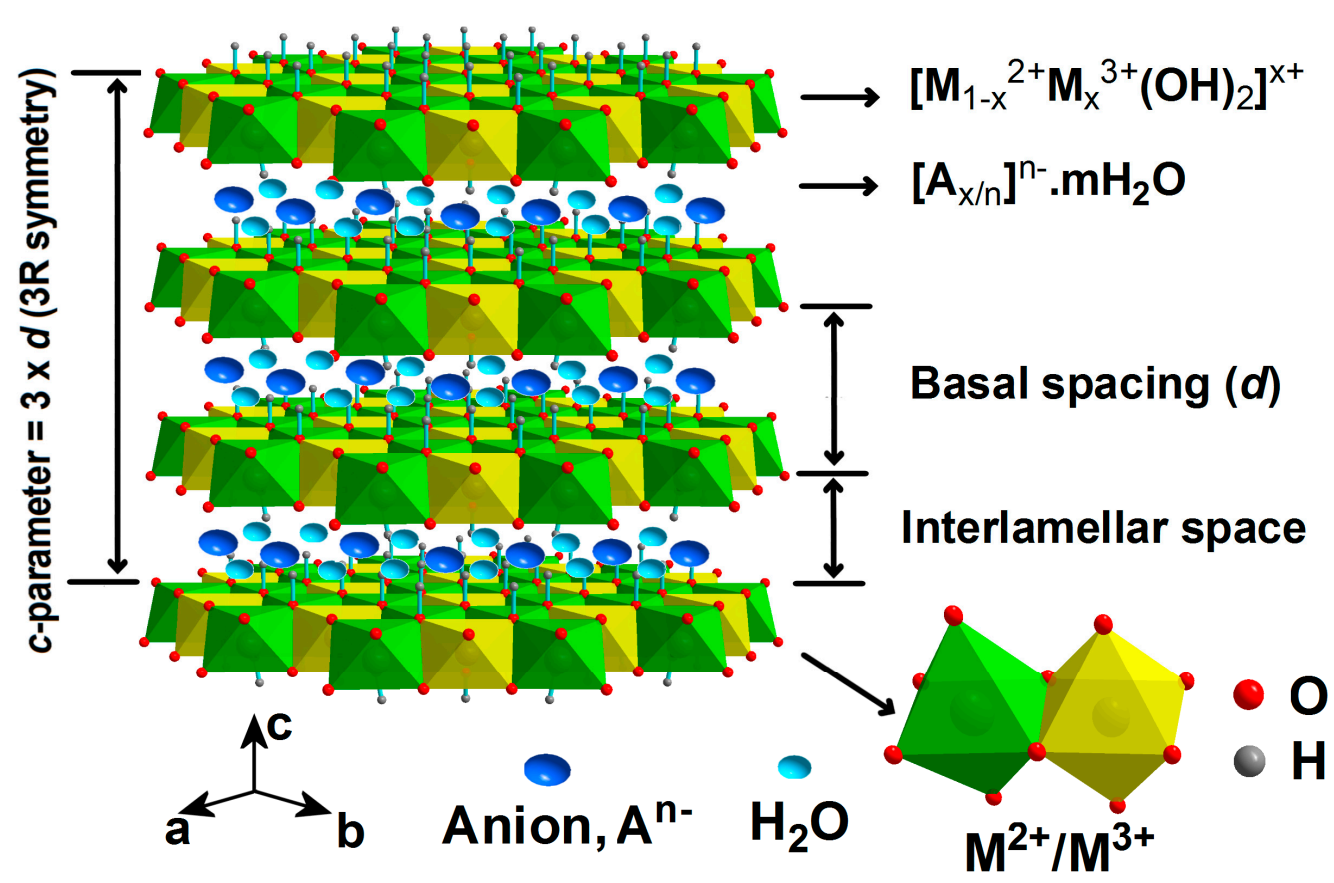

Figure 1. Schematic representation of the classical LDHs structure. Adapted from Ref. [11], Copyright 1999, Elsevier.

LDHs have been known for more than 150 years since the discovery of the mineral hydrotalcite, $\left[\mathrm{Mg}_{6} \mathrm{Al}_{2}(\mathrm{OH})_{16}\right] \mathrm{CO}_{3} \cdot 4 \mathrm{H}_{2} \mathrm{O}$ [11]. Partial substitution of the $\mathrm{Mg}^{\mathrm{II}}$ ions by $\mathrm{Al}^{\mathrm{III}}$ ions in hydrotalcite compositions leads to the formation of positively charged layers [12]. The layers can be stacked in two ways, either with a rhombohedral ( $3 R$ symmetry) or hexagonal cell ( $2 H$ symmetry). Hydrotalcite corresponds to the $3 R$ symmetry, while the $2 H$ analogue is referred to as manasseite [12,13]. In general, LDH can be synthesized in an aqueous medium employing a variety of methods including co-precipitation [14] hydrothermal conditions, [15] urea decomposition-homogeneous precipitation [16] or mechanochemical methods [17].

\section{LDH-Based Composite Materials}

In recent decades, the properties and functionality of LDHs have been adjusted by employing design principles in order to fabricate advanced materials which fulfill specific requirements for desirable applications in various fields [1]. For example, LDHs were used as additives in polymers [9], as adsorbents for water remediation [18], as precursors for functional materials, applied in the synthesis of pharmaceuticals [19], in photochemistry [20] and electrochemistry [21]. Moreover, LDHs prepared directly and their calcined mixed metal oxide (MMOs) products have been widely used as an actual solid base catalyst, and promising precursors or supports of catalysts in a variety of fields including organic synthesis, adsorption of organic wastes or heavy metals ions, and the decomposition of volatile organic compounds [22]. Recently, Kuroda and co-workers prepared novel LDH nanoparticles with exceptionally small particle sizes (ca. $10 \mathrm{~nm}$ ) by grafting a tripodal ligand of tris(hydroxymethyl) aminomethane (Tris) on the outer surface of LDH nanoparticles [23-25]. The Tris molecules were used as a surface-stabilizing agent by interacting with the LDH layer through multiple coordination, leading 
to effective control of the LDH nanoparticles' growth. The resulting small-sized LDH nanoparticles possess extremely high anion exchange abilities. Therefore, their work provides a potentially new design for the development of LDH-based composite materials.

\section{POM-LDH Composite Materials}

LDH materials possess relatively weak interlayer interactions and as a consequence they offer a remarkable opportunity for the development of methods that will allow the modulation of their functionality without compromising their structural features. In recent decades, increasing interest has been devoted to design and fabrication of novel intercalation composite materials with a variety of desirable physical and chemical properties. Recently, the adopted approach usually involves exfoliation of LDH layers and re-assembly in the presence of functional guest anions driven by electrostatic interactions. In particular, incorporation of catalytically active species, such as simple inorganic anions, complex ligands or biomolecules into the interlayer region of LDHs, is an effective immobilization method, and has been demonstrated to be an effective approach to enhance the catalytic stability and recyclability when compared to their corresponding homogeneous system. Moreover, the confined space of the LDHs interlayer region can impose restrictions to the geometry and accessibility of the catalytic active site in the interlayer region, resulting in the increased control of stereochemistry and dispersion of active components. Consequently, that led to increased reaction rates as well as modified product distributions [1]. For example, some intercalation composite materials have been applied in promotion of shape selective epoxidation reactions [26]. The intercalation of functional metal oxide-based anions with different molecular dimensions (for instance, $\mathrm{Mo}_{7} \mathrm{O}_{24}{ }^{6-}$ and $\mathrm{W}_{12} \mathrm{O}_{41}{ }^{10-}$ ) can control the gallery height of interacted materials. Tatsumi et al. reported different degrees of gallery accessibility for the substrates based on the gallery dimensions [27]. The $\mathrm{Mo}_{7} \mathrm{O}_{24}{ }^{6-}$-intercalated LDH exhibited slower epoxidation of cyclohexene owing to its smaller gallery height, preventing easy access to the inter-lamellar catalytic sites by the substrate. However, the decrease of the catalytic activity of cyclohexene was less remarkable for $\mathrm{W}_{12} \mathrm{O}_{41}{ }^{10-}$-intercalated $\mathrm{LDH}$ with a higher interlayer gallery. Additionally, the inherent basicity of brucite-like host LDH layers favored the production of epoxides over further hydrolysis, which leads to the formation of diols as principal products. Moreover, higher cis to trans ratio can be obtained for the oxidation of 2-hexene over intercalation composites. The observed enhancement of cis to trans ratio is probably due to the existence of steric constraints imposed by the robust interstitial environment. The gallery region is believed to provide a unique chemical environment for the modulation of selective catalytic reactions.

Polyoxometalates (POMs) are a diverse family of compounds mainly constructed via Mo, W, V or $\mathrm{Nb}$ etc. at their highest oxidation states. Their formation is mainly based on the appropriate charge to ionic radius ratio and charge density which: (i) prohibits infinite polymerization; (ii) promotes formation of $\pi$-bonds with the $\mathrm{O}^{2-}$ ligands; (iii) exhibits flexible and various coordination geometries. In the past decades, the properties of POMs have been extensively investigated due to a wide range of composition, sizes, rich redox chemistry, charge distribution and photochemistry to fulfill specific requirements in a variety of applications, including functional materials in catalysis, molecular electronics, magnetism, materials science and medicine [28-31]. Based on the above observations, various groups reported their efforts to design POM-based heterogeneous catalytic systems for the promotion of specific reactions. For example, Mizuno et al. reported the preparation, efficiency and stability of a peroxotungstate immobilized on ionic liquid-modified $\mathrm{SiO}_{2}$ heterogeneous catalyst for the epoxidation of a wide range of olefins [32]. In another case, Inumaru et al. demonstrated the efficiency of a $\mathrm{POM}-\mathrm{SiO}_{2}$ heterogeneous catalyst where $\mathrm{H}_{3} \mathrm{PW}_{12} \mathrm{O}_{40}$ species immobilized the channels of mesoporous silica decorated with hydrophobic alkyl groups. The produced catalyst not only revealed exceptional stability but also showed exceptionally high catalytic activity for ester hydrolysis in aqueous medium [33]. Various elegant approaches have been adopted for the design of appropriate components for the development of new POM-based heterogeneous catalytic systems. The use of LDH also attracted the attention of research groups due to their relatively facile preparation, under mild 
conditions, cost-effective preparation and most importantly their chemical and structural modularity. Recently, the manifestation of superior physicochemical properties of intercalation composites due to cooperative effects between LDHs and POMs attracted the interest of research groups since they have exhibited great advantages over both traditional POMs and LDH compounds, especially in catalytic applications. A series of intermolecular interactions, including electrostatic and hydrogen bond networks etc., can be developed between the brucite-like layers of LDHs and the intercalated POM anions. More importantly, the confinement effect of the LDH interlayer gallery prevents the POM species from leaching into the reaction mixture and increasing the selectivity of the catalytic reaction. A general structure of the POM-LDH composite is illustrated in Figure 2.

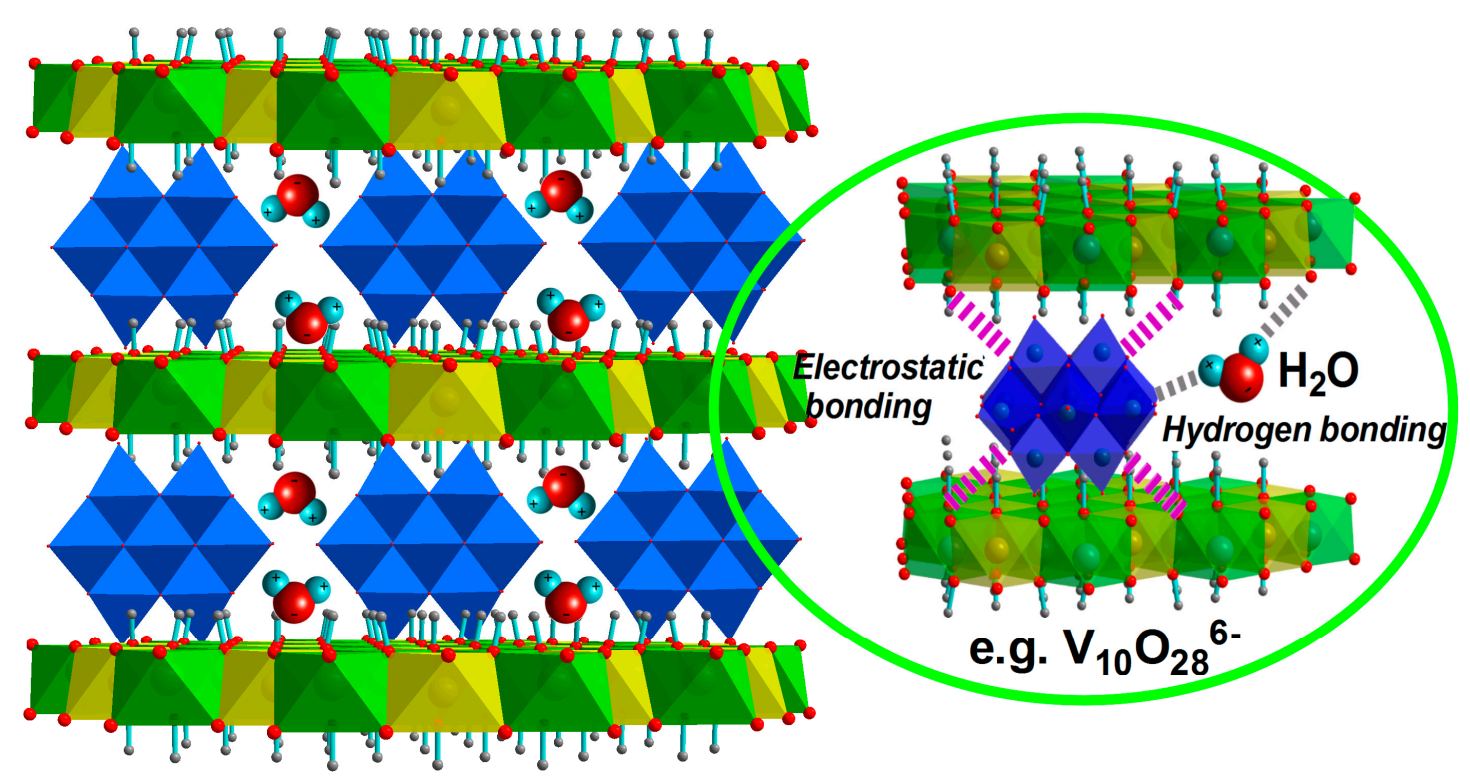

Figure 2. Schematic representation of POM-LDHs structure (e.g., $\mathrm{V}_{10} \mathrm{O}_{28}{ }^{6-}$ intercalated in $\mathrm{ZnAl}-\mathrm{LDH}$ ). Adapted from Ref. [12], Copyright 2014, Elsevier.

\subsection{Synthesis of POM/LDH Composites}

In 1988, Pinnavaia et al. reported the preparation of POM-LDH composite $\mathrm{Zn}_{2} \mathrm{Al}^{-} \mathrm{V}_{10} \mathrm{O}_{28}$ by ion exchange of the $\mathrm{LDH}-\mathrm{Cl}^{-}$with $\left[\mathrm{NH}_{4}\right]_{6}\left[\mathrm{~V}_{10} \mathrm{O}_{28}\right] \cdot 6 \mathrm{H}_{2} \mathrm{O}$ at $\mathrm{pH}$ 4.5. As shown in Figure 3, the resulting composite possesses a basal spacing of $11.9 \AA$, corresponding to a gallery height of $7.1 \AA$, indicating that the decavanadate's $C_{2}$ axis is aligned parallel to LDH host layers. The group verified further the successful intercalation of the $\mathrm{V}_{10} \mathrm{O}_{28}{ }^{6-}$ cluster using ${ }^{51} \mathrm{~V}$ MAS-NMR spectrum of intercalated $\mathrm{Zn}_{2} \mathrm{Al}-\mathrm{V}_{10} \mathrm{O}_{28}$ by comparing the relevant spectrum of its ammonium salt, which does not observe obvious change of the chemical shifts; additionally, all chemical parameters are qualitatively similar, which indicates that the decavanadate retains its structural integrity in the intercalated state [34]. This observation demonstrates that the LDHs with high-charge density can be intercalated by guest POM anions for the first time, providing the intercalation of POMs with relatively high charge density. Moreover, the authors reported that Keggin species and their derivatives such as $\mathrm{H}_{2} \mathrm{~W}_{12} \mathrm{O}_{4} \mathrm{O}^{6-}$ and $\mathrm{BVW}_{11} \mathrm{O}_{40}{ }^{7-}$ also can be successfully intercalated into $\mathrm{LDH}$, affording the resulting interacted derivatives with gallery heights of $9.6 \AA$ A. Since then, the development of new methodologies for the preparation of POM-LDH composite materials and the investigation of their functionalities has increased exponentially.

To date, several synthetic approaches can be used for the preparation of POM-LDH composites. Among the most developed ones are the ion exchange synthetic pathway [34-37]; co-precipitation [38], reconstitution [39] et al. and have been discussed into detail elsewhere. Here, we will focus our discussion on the following two methods developed recently by Song et al. [40]. 


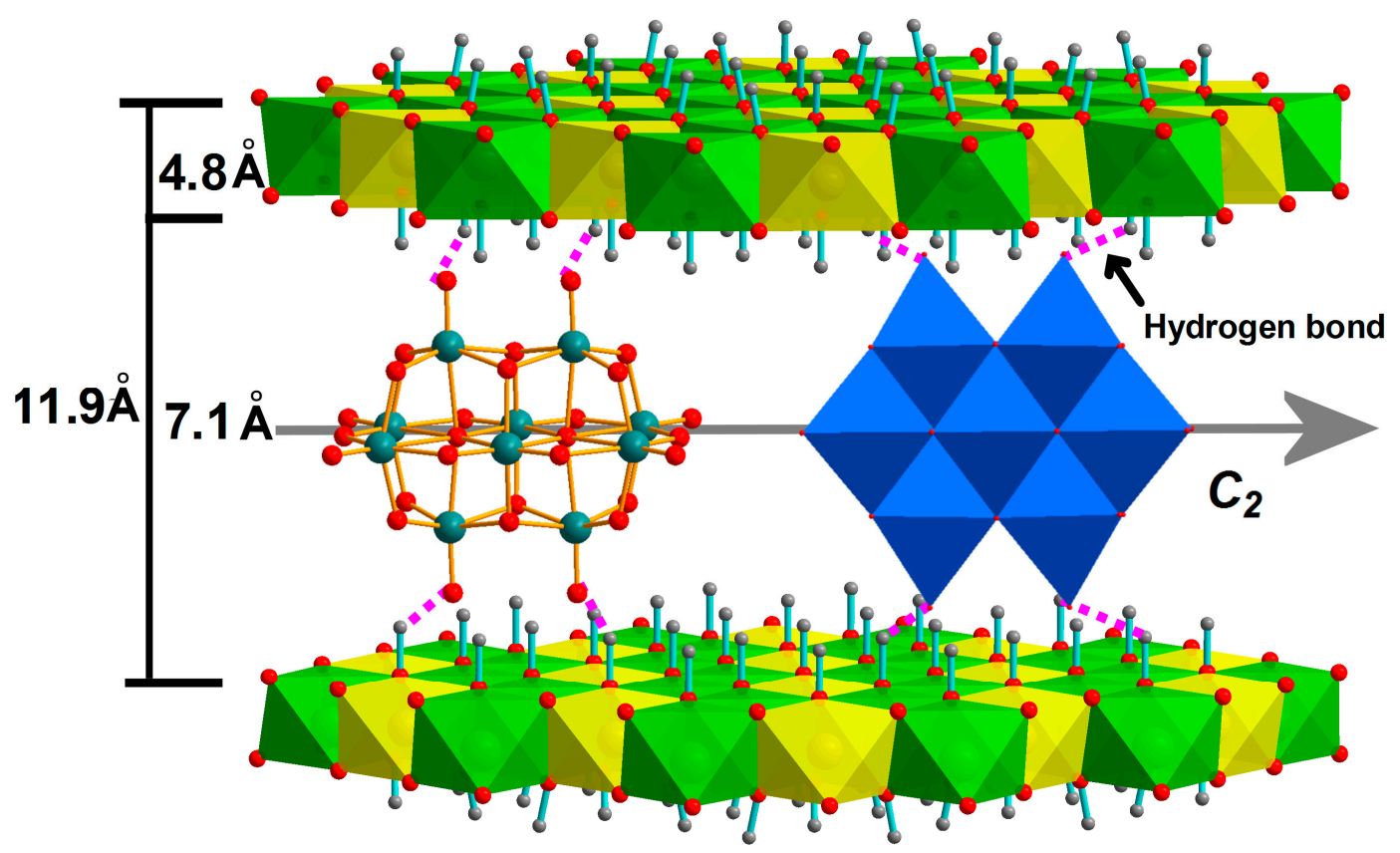

Figure 3. Orientation of decavanadate anion, $\mathrm{V}_{10} \mathrm{O}_{28}{ }^{6-}$, in the interlayer region of layered double hydroxides, with its 'main' $C_{2}$ axis aligned parallel to the brucite-like layers. Adapted from Ref. [12], Copyright 2014, Elsevier.

\subsubsection{Host Layer Modification Method}

Although POM-intercalated LDH composite materials exhibit superior performance and modular functionality compared to individual components, the relevant intercalation process faces serious challenges: (1) the preparation of POM-LDH composites without impurities using traditional synthetic methods such as reconstitution and co-precipitation pathways is an extremely challenging task; (2) POM intercalation is directly related to the geometry, charge density and overall size of POMs. Thus, POM anions that exhibit negative charge below four, such as the classical Keggin of $\left[\mathrm{PW}_{12} \mathrm{O}_{40}\right]^{3-}$, are very difficult to intercalate into LDH galleries using conventional synthetic methods; (3) LDHs exhibit a high affinity for smaller anions such as $\mathrm{CO}_{3}{ }^{2-}$; thus, ion exchange reactions for preparation of POMs intercalated into LDHs is not favored under air. These issues significantly limit the chemical tunability and intercalation ability of LDH-based materials. Inspired by Kuroda et al. work of LDH-NPs with exceptionally small size and enhanced anion exchangeability by modifying the surface using a tripodal ligand Tris [23-25]. In a similar manner, our group developed recently a novel approach where the host layer modified with tris(hydroxymethyl)aminomethane (Tris) prior to the intercalation of the classical Keggin cluster of $\mathrm{Na}_{3} \mathrm{PW}_{12} \mathrm{O}_{40} \cdot 15 \mathrm{H}_{2} \mathrm{O}\left(\mathrm{Na}-\mathrm{PW}_{12}\right)$ under ambient conditions without the necessity of degassing $\mathrm{CO}_{2}$ (Figure 4) [41]. Tris-LDH- $\mathrm{CO}_{3}(2 \mathrm{mg} / \mathrm{mL}$ ) was re-dispersed in $\mathrm{Na}_{3}\left[\mathrm{PW}_{12} \mathrm{O}_{40}\right]$ aqueous $(0.1 \mathrm{M})$ and then reacted for $2 \mathrm{~h}$ at room temperature. The reaction mixture was then filtered, washed by water and acetone, and dried at $60^{\circ} \mathrm{C}$ to obtain the Tris-LDH-PW 12 . The host layer modification method can modulate the host-guest interactions including electrostatic interactions and hydrogen bonding between host layers and guests in interlayer gallery and consequently promote the ion exchange process. 


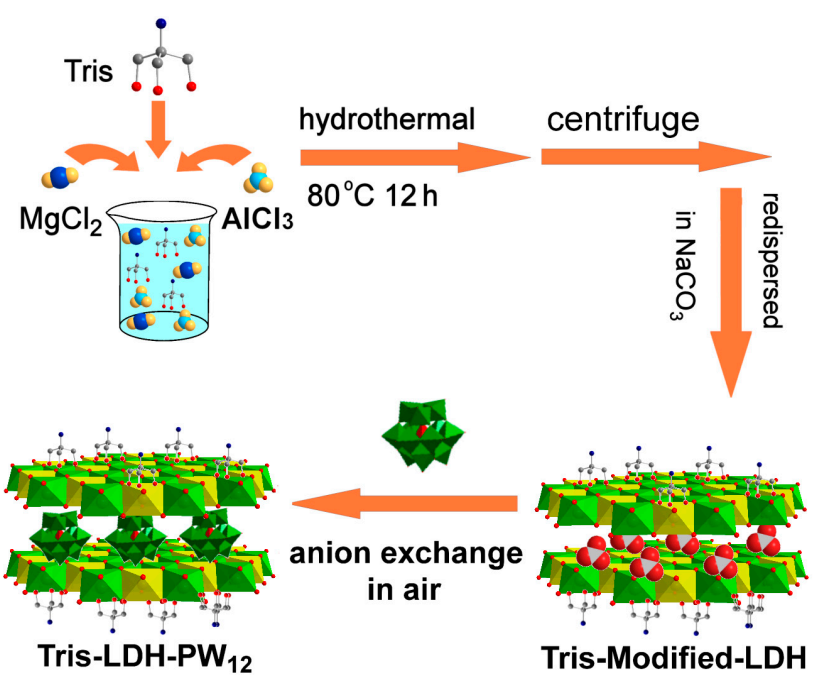

Figure 4. Schematic representation of the host layer modification method to prepare POM-LDH composite (Tris-LDH-PW 12 ). Adapted from Ref. [41], Copyright 2014, Royal Society of Chemistry.

\subsubsection{Exfoliation Assembly Method}

In the past few years, the delaminated LDHs have been employed successfully in the design and fabrication of advanced functional materials. For example, Kim et al. [42] reported a design strategy for the assembly of quantum dots (QDs) that was encapsulated by delaminated LDH nanosheets in formamide via electrostatic interactions. Hwang et al. [43] reported the preparation of mesoporous nanohybrids with excellent photocatalytic activity, by the assembly of positively charged 2D ZnCr-LDH nanosheets and negatively charged layered titanium oxide. Inspired by these exfoliation and assembly strategies of LDH nanosheets, we envisaged that POM clusters, as a class of discrete anionic metal oxides with high negative charge density, should be able to assemble with LDH nanosheets using a similar approach. As shown in Figure 5, the first step involves the exfoliation of the $\mathrm{LDH}-\mathrm{NO}_{3}$ precursor in formamide solvent at 1:1 ratio ( $1 \mathrm{mg} \mathrm{LDH}-\mathrm{NO}_{3}$ per $\mathrm{mL}$ of formamide) in a flask; the mixture was sealed after purging with $\mathrm{N}_{2}$ in order to avoid carbonate contamination. The reaction mixture becomes clear upon quantitative exfoliation of the LDH precursor; subsequently, addition of POM clusters triggers the assembly of the components towards the formation of the intercalated material. The restacked POM-LDH composite was collected by filtration and washed thoroughly with ethanol and water, and dried under vacuum [44]. It is remarkable that the exfoliation assembly pathway provides a novel and rational method to fabricate composite functional materials with a desirable and precisely controlled nanostructure. Moreover, this method can prevent metal ions leaching out of the host layer during the intercalation process and thereby successfully control the final metal ions ratio (for example, $\mathrm{Mg}^{\mathrm{II}} / \mathrm{Al}^{\mathrm{III}}$ ) in the resulting POM-LDHs composite without co-formation of impurity phases.

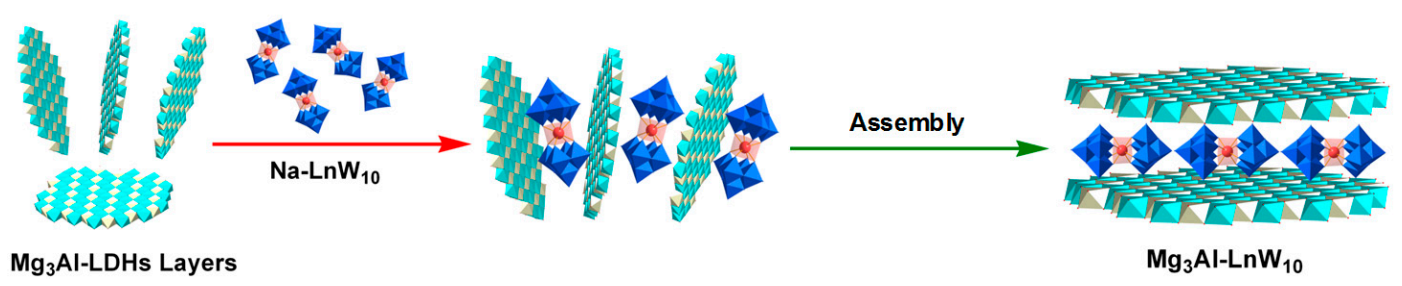

Figure 5. The preparation process of POM-LDHs composites $\left(\mathrm{Mg}_{3} \mathrm{Al}-\mathrm{LnW}_{10}\right)$ using the Exfoliation assembly method. Reproduced from Ref. [44], Copyright 2014, Elsevier. 


\subsection{Structural Features}

POMs' structural diversity in terms of size and features can be used constructively for the engineering of the structure of the composite materials that exhibit specific gallery height; additionally POMs with relatively high-charge density should afford large lateral anion spacing, consequently providing the chance to access the LDH gallery region [34]. Therefore, POMs can be viewed as ideal functional guest anions for intercalation, which offers the opportunity for modulation and fine-tuning of the composite material's properties. Additionally, synergistic effects between the constituents of the POM intercalated LDH composites lead to performance enhancement induce emergence of new functionality as well as offer the opportunity to expand the areas of application [12]. For instance, the intercalation of POM clusters into LDH layers in aqueous media results in an insoluble self-assembled product where the POM cluster retains their catalytic properties and can perform efficiently as component of the heterogeneous system. The combinatorial effect induced by the structural and chemical characteristics of the POM-intercalated LDH materials leads to the performance enhancement of the final product.

\subsection{Oxidation Catalyst}

As shown in Figure 6, we prepared a series of POM-LDH composites $\mathrm{Mg}_{3} \mathrm{Al}-\mathrm{P}_{2} \mathrm{~W}_{17} \mathrm{X}$ $\left(\mathrm{X}=\mathrm{Mn}^{\mathrm{III}} \mathrm{Fe}^{\mathrm{III}}, \mathrm{Zn}^{\mathrm{II}}, \mathrm{Co}^{\mathrm{II}}, \mathrm{Cu}^{\mathrm{II}}, \mathrm{Ni}^{\mathrm{II}}\right)$ by intercalating a Dawson polyoxometalate (POM) species $\left[\alpha_{2}-\mathrm{P}_{2} \mathrm{~W}_{17} \mathrm{O}_{61}\left(\mathrm{X} \cdot \mathrm{OH}_{2}\right)\right]^{n-}\left(\left[\mathrm{P}_{2} \mathrm{~W}_{17} \mathrm{X}\right]^{n-}, n=7\right.$ or 8) into a $\mathrm{Mg}_{3} \mathrm{Al}$-suberic precursor [36]. Catalytic tests for the sulfoxidation of various sulfides demonstrated that $\mathrm{Mg}_{3} \mathrm{Al}-\mathrm{P}_{2} \mathrm{~W}_{17} \mathrm{Zn}$ exhibits superior catalytic efficiency and selectivity than the individual POM or LDH precursors under mild conditions. The uniform and well-ordered dispersion of POM clusters in the confined gallery of LDHs as well as the multiple interactions between POMs and LDHs contribute to the excellent catalytic performance. Furthermore, $\mathrm{Mg}_{3} \mathrm{Al}-\mathrm{P}_{2} \mathrm{~W}_{17} \mathrm{Zn}$ is stable and can be easily separated from the reaction system. The recycled $\mathrm{Mg}_{3} \mathrm{Al}-\mathrm{P}_{2} \mathrm{~W}_{17} \mathrm{Zn}$ material retains its structural features and composition of the individual components, which has been confirmed by Fourier transform infrared (FT-IR), X-ray diffraction, ${ }^{31} \mathrm{P}$ NMR, and X-ray photoelectron spectroscopy characterization. The scaled-up experiment provided further support for its potential use for industrial applications.
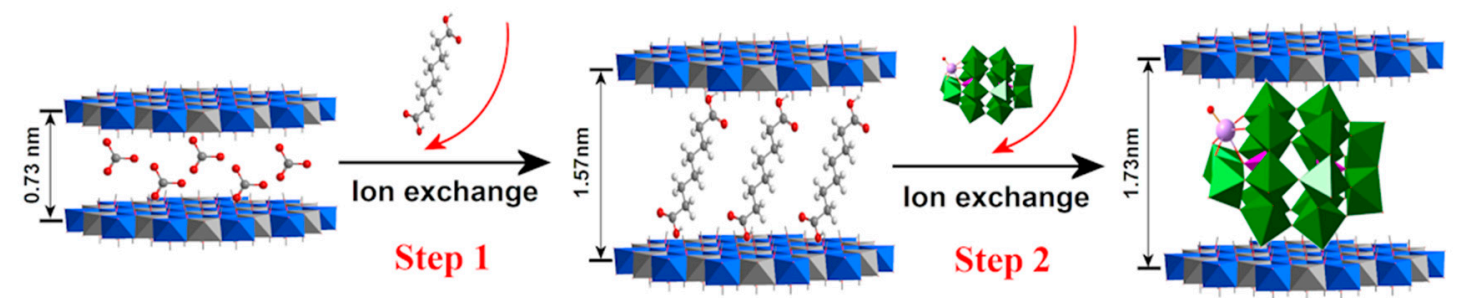

Figure 6. Schematic of the synthesis of $\left[\alpha_{2}-\mathrm{P}_{2} \mathrm{~W}_{17} \mathrm{O}_{61}\left(\mathrm{X} \cdot \mathrm{OH}_{2}\right)\right]^{n-}$ intercalated into LDHs. Adapted from Ref. [36], Copyright 2015, American Chemical Society.

Water pollution from dyes is a serious environmental problem due to the inherent difficulties for their efficient degradation in conjunction with their high chemical stability [45]. Continuous research interest has been focused on the development of methods to treat dye effluents. Recently, a series of POM-intercalated LDHs (Tris-LDHs- $\mathrm{PW}_{12}$, Tris-LDH-LaW 10 and Tris-LDH- $\mathrm{P}_{2} \mathrm{~W}_{18}$ ) were prepared by employing the host layer modification method under ambient conditions without the necessity of degassing $\mathrm{CO}_{2}$.

The heterogeneous catalytic systems were used for the efficient degradation of methylene blue $(\mathrm{MB})$, rhodamine $\mathrm{B}(\mathrm{RB})$ and crystal violet $(\mathrm{CV})$ solution, where Tris-LDHs-PW $\mathrm{PW}_{12}$ exhibits the best performance in the presence of $\mathrm{H}_{2} \mathrm{O}_{2}$ [46]. As shown in Figure 7, almost complete dye degradation can be achieved within $320 \mathrm{~min}, 140 \mathrm{~min}$, and $5 \mathrm{~min}$ for $\mathrm{RB}, \mathrm{MB}$, and $\mathrm{CV}$, respectively. Their 
degradation products have been detected and identified as non- or less-toxic anions such as $\mathrm{SO}_{4}{ }^{2-}$, $\mathrm{NO}_{3}{ }^{-}, \mathrm{C}_{2} \mathrm{O}_{4}{ }^{2-}, \mathrm{CHO}^{2-}$ and $\mathrm{C}_{2} \mathrm{H}_{3} \mathrm{O}_{2}{ }^{2-}$. Additionally, degradation of the mixture of $\mathrm{RB}, \mathrm{CV}$ and $\mathrm{MB}$ by Tris-LDHs-PW $\mathrm{PW}_{12}$ follows the order of $\mathrm{CV}>\mathrm{MB}>\mathrm{RB}$, which is directly related to the designed accessible area of the interlayer space.

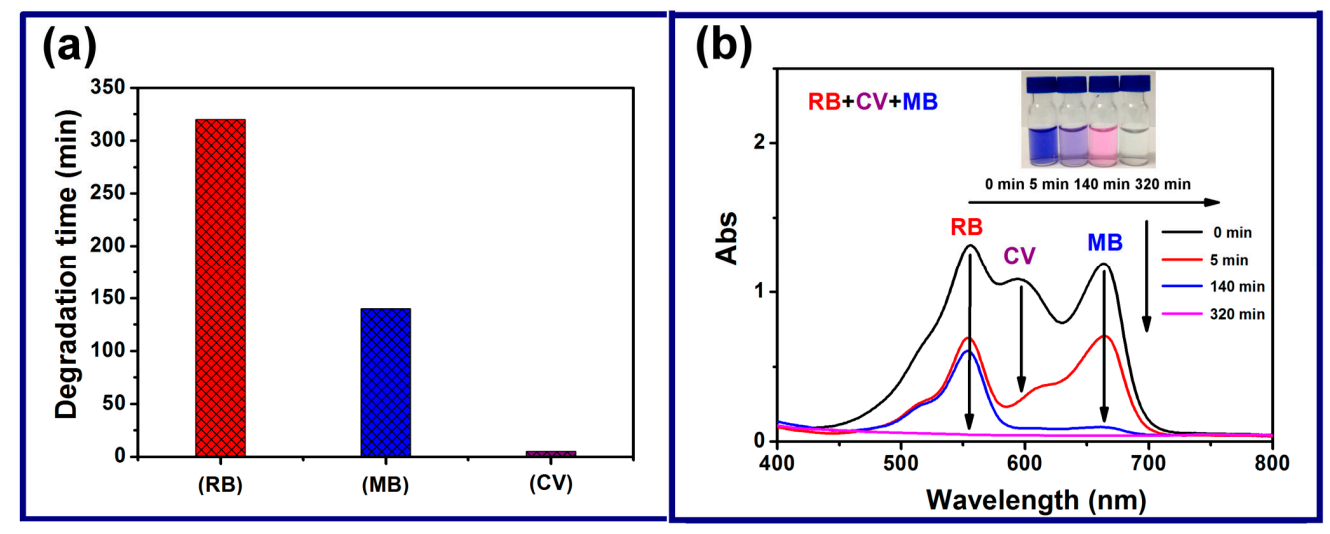

Figure 7. (a) Degradation time of different dyes. Experimental condition: Tris-LDH-PW $1250 \mathrm{mg}$; $\mathrm{H}_{2} \mathrm{O}_{2}=500 \mu \mathrm{L} ; \mathrm{T}=30^{\circ} \mathrm{C}$; Dye $=10 \mathrm{mg} / \mathrm{L}(50 \mathrm{~mL}) ;(\mathbf{b})$ The UV - Vis spectra of degradation mixed dyes. Experiment condition: Tris-LDH-PW $1250 \mathrm{mg} ; \mathrm{H}_{2} \mathrm{O}_{2}=500 \mu \mathrm{L}$; total dye $=10 \mathrm{mg} / \mathrm{L}(50 \mathrm{~mL}$, each dye $=$ $3.33 \mathrm{mg} / \mathrm{L}) ; \mathrm{T}=30^{\circ} \mathrm{C}$. Reproduced from Ref. [46], Copyright 2015, WILEY-VCH.

On the basis of increasing environmental impact of sulfur-containing chemicals in fuel oils, the development of efficient and environmentally friendly deep desulfurization processes has been flagged as an urgent global challenge $[47,48]$. In recent years, POM-LDH composites have been widely used in green chemistry industry $[40,46]$, and currently, catalytic oxidation desulfurization has become an important task for environmental pollution control. However, the traditional hydro-desulfurization (HDS) processes employed for the removal of DBT, 4,6-DMDBT and BT etc. are quite challenging. Furthermore, the HDS processes need harsh conditions, (high temperature and pressure regimes), thus restricting its wide- and large-scale application. Therefore, the removal of sulfur-containing compounds from fuel oils under mild conditions is a serious issue. We used Tris-LDH-PW 12 for extraction and catalytic oxidation/desulfurization of fuel oils. We demonstrated that deep desulfurization of DBT can be achieved in $25 \mathrm{~min}$ at $75^{\circ} \mathrm{C}$ using $\mathrm{H}_{2} \mathrm{O}_{2} /$ DBT/Cat $=100: 20: 1$. Also recently, we developed an intercalated hybrid material $\mathrm{Mg}_{3} \mathrm{Al}-\mathrm{IL}-\mathrm{EuW}_{10}$ that incorporates covalently anchored ionic liquids, and exhibits efficient deep desulfurization and high selectivity for the removal of 4,6-DMDBT and DBT etc.

In addition to sulfur compounds, diesel oil, gasoline and jet fuel contain many nitrogen-containing compounds [49]; the combustion of these substances will release large amounts of nitrogen oxides, leading to the formation of acid rain with serious environmental consequences [50]. Although the concentration of nitrogen-containing compounds in fuel oils is relatively low, the competition with sulfur-containing components for the active sites of the catalysts [51,52], can lead to the inhibition of the deep desulfurization process. Therefore, deep desulfurization and denitrogenation is of great significance for the development of clean oil products, and is a challenging task. We also demonstrated that the Tris-LDH-LaW 10 composite could be used as green and highly efficient catalyst for simultaneous deep hydro-desulfurization and hydro-denitrogenation of complex model oil mixtures under mild conditions. As shown in Figure 8, the catalytic system of $\mathrm{H}_{2} \mathrm{O}_{2} /\left[\right.$ bmim] $\mathrm{BF}_{4} /$ Tris-LDH-LaW ${ }_{10}$ can complete concurrent deep desulfurization and denitrogenation in $60 \mathrm{~min}$ with $\mathrm{S}$ and $\mathrm{N}$ contents less than 10 and $1 \mathrm{ppm}$, respectively, at $65^{\circ} \mathrm{C}$ [53]. 


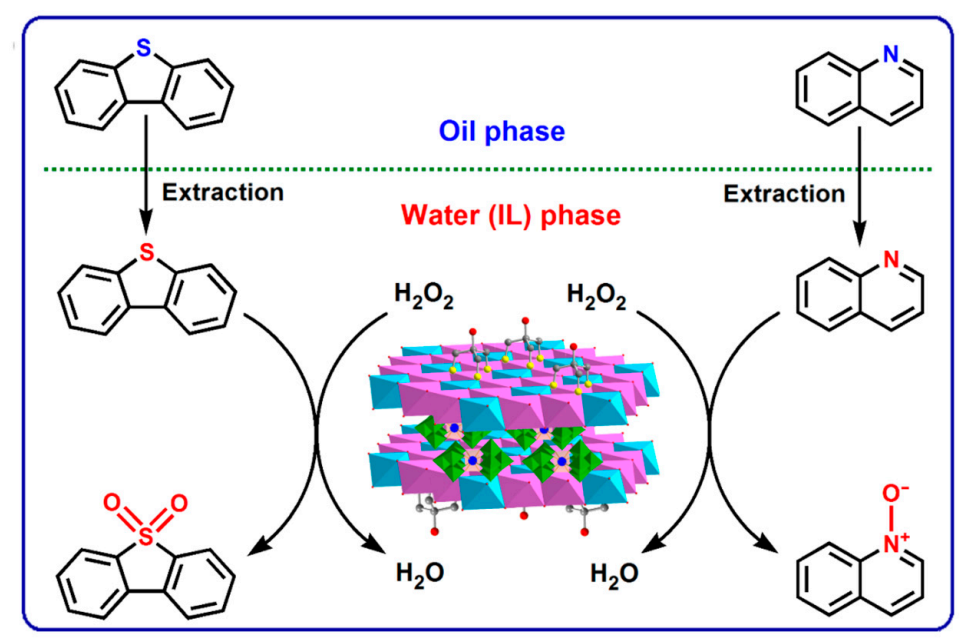

Figure 8. Proposed schematic of extraction and catalytic desulfurization and denitrogenation route with $\mathrm{H}_{2} \mathrm{O}_{2} /\left[\mathrm{bmim}_{\mathrm{B}} \mathrm{BF}_{4} /\right.$ TrisLDH-LaW 10 . Adapted from Ref. [53], Copyright 2016, Royal Society of Chemistry.

Another family of organic compounds that received much attention in recent decades is the heterocyclic $\mathrm{N}$-oxides because of their wide use as versatile synthetic intermediates, their biological significance, their use as protecting groups, as oxidants, as auxiliary agents, as ligands in metal complexes, as surrogates for heterocyclic boronic acids, and catalysts [54,55]. Our group successfully prepared a Lewis acid POM-LDH catalyst by intercalating $\left[\mathrm{La}\left(\mathrm{PW}_{11} \mathrm{O}_{39}\right)_{2}\right]^{11-}$ anions into LDH modified with tris(hydroxymethyl)aminomethane (Tris) [56]. As shown in Figure 9, the resulting Tris-LDH-La(PW $\left(\mathrm{PW}_{11}\right)_{2}$ composite shows excellent selectivity, high yield, and high efficiency for the $\mathrm{N}$-oxidation of pyridines and its derivatives at room temperature in the presence of $\mathrm{H}_{2} \mathrm{O}_{2}$. Moreover, Tris-LDH-La( $\left(\mathrm{PW}_{11}\right)_{2}$-based catalysts have been applied in the denitrogenation of a model oil mixture in the presence of $\mathrm{H}_{2} \mathrm{O}_{2}$ and 1-butyl-3-methylimidazolium tetrafluoroborate. Denitrogenation can be achieved in $40 \mathrm{~min}$ at $75^{\circ} \mathrm{C}$.

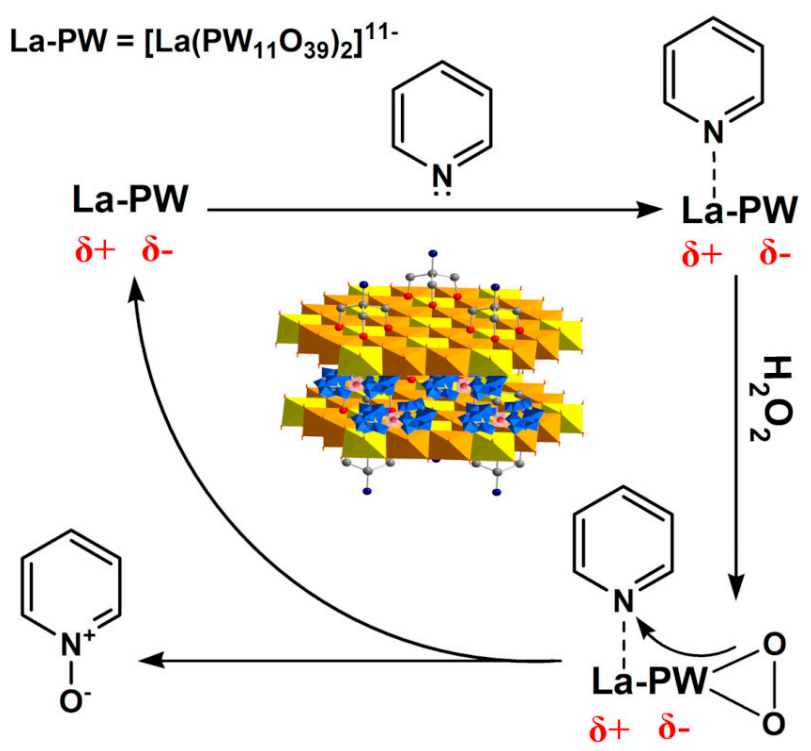

Figure 9. Proposed reaction mechanism for oxidation of pyridines by Tris-LDH-La( $\left(\mathrm{PW}_{11}\right)_{2}$. Adapted from Ref. [56]. Copyright 2015, Willey-VCH. 
One-pot cascade reactions are highly desirable for organic synthetic chemists [57,58], because they can drastically simplify multi-step synthetic pathways and thereby reduce the waste production and energy consumption [59,60]. A feasible pathway for efficient progression of a tandem reaction is based on the design and fabrication of bifunctional catalyst with spatially isolated multiple active sites, promoting simultaneously different reactions within the same system. The Knoevenagel reaction between an aldehyde/ketone and active methylene-containing compounds is one of the most important reactions leading to carbon-carbon bond formation [61,62], which has been utilized for the syntheses of important products or intermediates for pharmaceuticals, perfumes and calcium antagonists $[63,64]$. Taking into consideration the fact that POMs possess excellent redox properties while the LDHs have a number of active basic sites that can efficiently promote Knoevenagel condensation reactions, we envisaged that a POM-LDH composite could be used as a novel bifunctional catalyst, which can catalyze both Knoevenagel reactions and the oxidation of substrates. Recently, we prepared a series of bifunctional catalysts of the general formula Tris-LDH- $\mathrm{X}_{4}\left(\mathrm{PW}_{9}\right)_{2}(\mathrm{X}=\mathrm{Mn}, \mathrm{Fe}, \mathrm{Co}, \mathrm{Ni}, \mathrm{Cu}$ and $\mathrm{Zn})$ via intercalating $\left[\mathrm{X}_{4}\left(\mathrm{H}_{2} \mathrm{O}\right)_{2}\left(\mathrm{PW}_{9} \mathrm{O}_{34}\right)_{2}\right]^{10-}$ anions into the Tris-modified $\mathrm{LDH}$ using the host layer modification method reported above [65]. Among all the members of the designed bifunctional catalysts, the Tris-LDH- $\mathrm{Zn}_{4}\left(\mathrm{PW}_{9}\right)_{2}$ composite revealed the highest activity and selectivity in the tandem reaction for the preparation of benzylidene ethyl cyanoacetate via an oxidation-Knoevenagel condensation between benzyl alcohol and ethyl cyanoacetate under mild and solvent-base-free conditions. As shown in Figure 10, initially, the formation of benzaldehyde can be promoted by the POM species in the presence of $\mathrm{H}_{2} \mathrm{O}_{2}$ via oxidation of benzyl alcohol. Simultaneously, the basic sites from Tris and LDH layers promote the activation of ethyl cyanoacetate to form a nucleophile, which rapidly reacts with the benzaldehyde leading to the formation of the corresponding benzylidene ethyl cyanoacetate product.

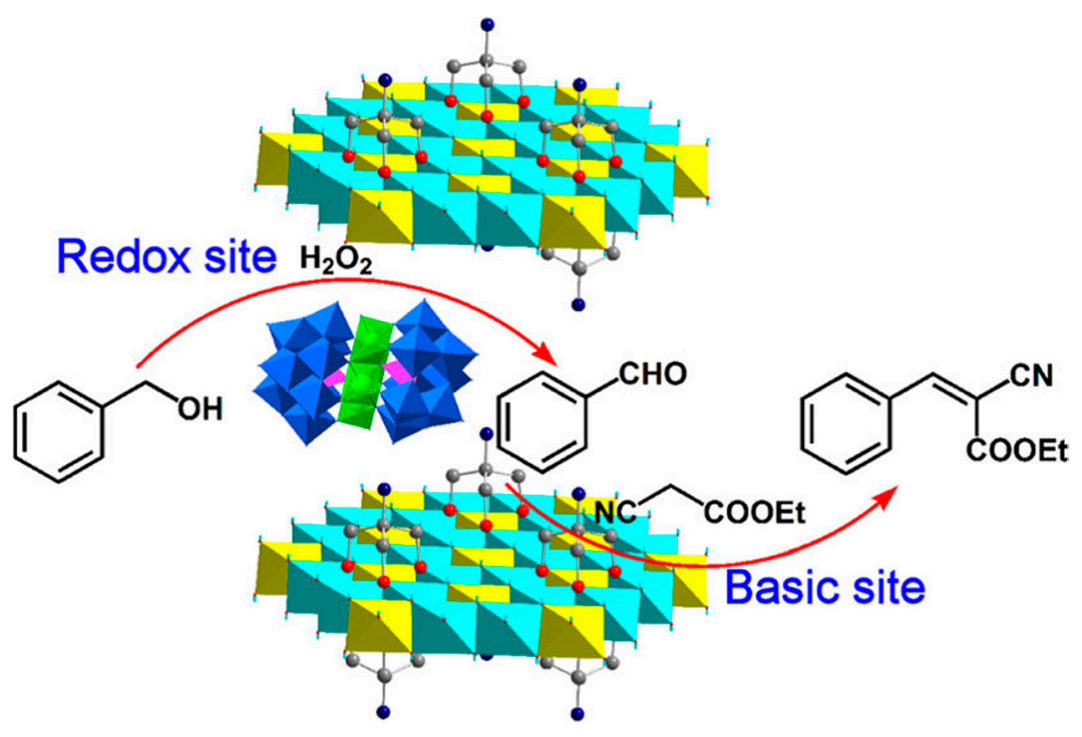

Figure 10. Schematic of the reaction pathway of the one-pot tandem reaction catalyzed by Tris-LDH- $\mathrm{Zn}_{4}$ $\left(\mathrm{PW}_{9}\right)_{2}$. Reproduced from Ref. [65], Copyright 2016, WILEY-VCH.

The poor mass transfer between the active components of the intercalated catalysts and organic substrates is one of the main challenges that limit their further application. On the basis of summarizing the traditional intercalation catalysts of POMs and in order to improve the mass transfer, we reported the design and synthesis of a novel intercalation POM-LDH catalyst $\left(\mathrm{Mg}_{3} \mathrm{Al}-\mathrm{ILs}-\mathrm{C}_{8}-\mathrm{LaW}_{10}\right)$ by intercalating $\mathrm{Na}_{9} \mathrm{LaW}_{10} \mathrm{O}_{36} \cdot 32 \mathrm{H}_{2} \mathrm{O}\left(\mathrm{LaW}_{10}\right) \mathrm{POM}$ clusters into LDHs, which have been covalently modified with ionic liquids (ILs) [66]. As shown in Figure 11, the grafting of ILs on the LDH not only induces flexibility to the catalyst but also allows easy accessibility of the substrates to the active center 
during the liquid-solid reaction system, which improves dramatically the mass transfer. The catalyst $\mathrm{Mg}_{3} \mathrm{Al}$-ILs- $\mathrm{C}_{8}-\mathrm{LaW}_{10}$ demonstrates high activity and selectivity for the epoxidation of various allylic alcohols in the presence of $\mathrm{H}_{2} \mathrm{O}_{2}$. For example, trans-2-hexen-1-ol undergoes up to $96 \%$ conversion and $99 \%$ selectivity for the formation of epoxide at $25^{\circ} \mathrm{C}$ in $2.5 \mathrm{~h}$. The $\mathrm{Mg}_{3} \mathrm{Al}-\mathrm{ILs}-\mathrm{C}_{8}-\mathrm{LaW}_{10}$ composite material constitutes one of the most efficient heterogeneous catalysts for the epoxidation of allylic alcohols (including the hydrophobic allylic alcohols with long alkyl chains) reported so far.

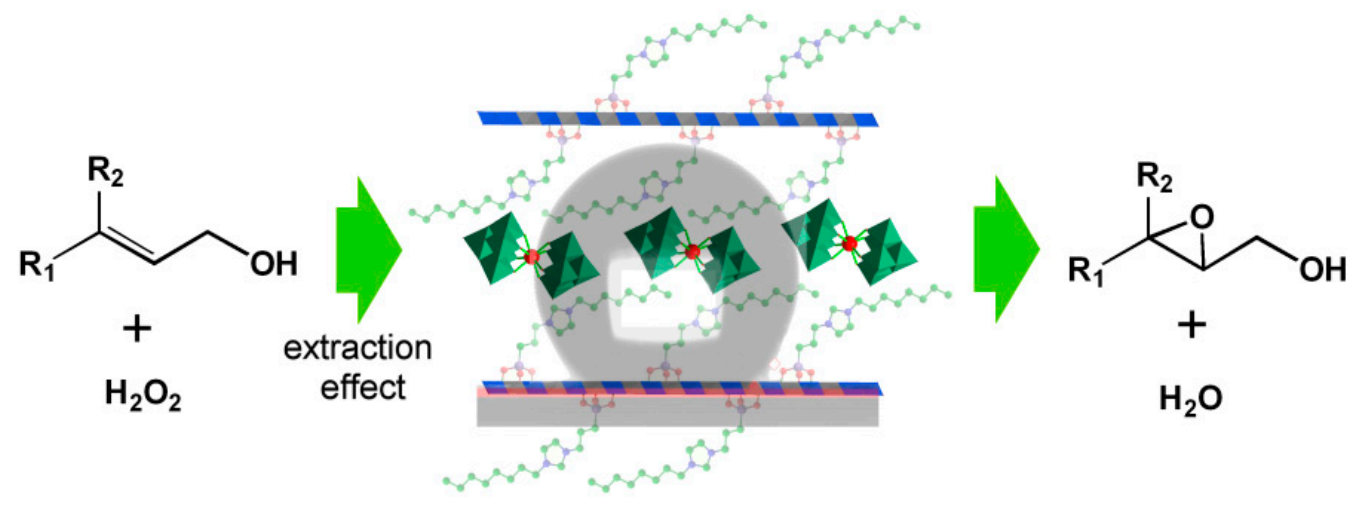

\section{$\mathrm{Mg}_{3} \mathrm{Al}$-ILs-Cn-LaW 10}
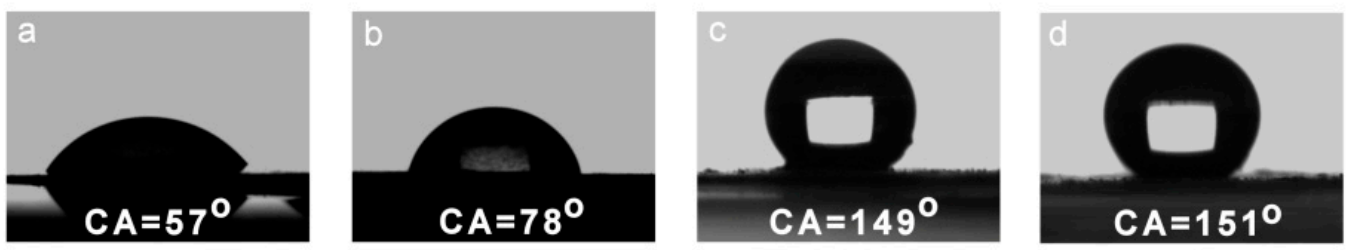

Figure 11. Top: schematic diagram of the catalytic process; Bottom: the water contact angle measurements of: (a) $\mathrm{Mg}_{3} \mathrm{Al}-\mathrm{LaW}_{10}$; (b) $\mathrm{Mg}_{3} \mathrm{Al}-\mathrm{ILs}-\mathrm{C}_{4}-\mathrm{LaW}_{10}$; (c) $\mathrm{Mg}_{3} \mathrm{Al}-\mathrm{ILs}_{-}-\mathrm{C}_{8}-\mathrm{LaW}_{10}$; and (d) $\mathrm{Mg}_{3} \mathrm{Al}-\mathrm{ILs}-\mathrm{C}_{12}-\mathrm{LaW}_{10}$ Reproduced from Ref. [66], Copyright 2017, WILEY-VCH.

\subsection{Acid-Base Synergistic Catalyst}

Aldoximes and ketoximes are valuable chemical and biopharmaceutical intermediates that are widely applied in chemical synthesis [67], and they are usually synthesised by oximation of aldehydes or ketones using mineral salt of hydroxylamine, such as $\mathrm{NH}_{2} \mathrm{OH} \cdot \mathrm{HCl}$ or $\mathrm{NH}_{2} \mathrm{OH} \cdot \mathrm{H}_{2} \mathrm{SO}_{4}$ [68]. However, the abovementioned pathway suffers from two drawbacks: the high cost of hydroxylamine along with the increasing environmental concern accompanied with the disposal of co-produced large amounts of inorganic salts [69]. To overcome such problems, many efforts have been dedicated to the developpment of salt-free oximation methods using aqueous $\mathrm{H}_{2} \mathrm{O}_{2}$ as an oxidant in the oximation reactions of aldehydes to aldoximes and Ketoximes [70,71]. An additional key issue associated with the formation of aldoximes is that they can undergo an acid-catalyzed dehydration to yield nitriles or go through an acid-catalyzed Beckmann rearrangement to form amides, leading to decreased product selectivity.

It has been observed that the water-soluble POM cluster $\mathrm{Na}_{12}\left[\mathrm{WZn}_{3}\left(\mathrm{H}_{2} \mathrm{O}\right)_{2}\left[\mathrm{ZnW}_{9} \mathrm{O}_{34}\right)_{2}\right] \cdot 46 \mathrm{H}_{2} \mathrm{O}$ can act as an efficient catalyst to promote the oximation of aldehydes in the presence of $\mathrm{H}_{2} \mathrm{O}_{2}$ [72] . However, the inherent acidity of POMs can promote side reactions and induce further transformations. Therefore, achieving high selectivity during the oximation reaction of aromatic aldehydes remains a challenging task. Li and co-authors $[37,73]$ reported that the self-assembled POM-intercalated LDHs are active catalysts for the epoxidation reactions, and the basic hydroxyl groups of the LDHs can prevent subsequently the acid-catalyzed ring opening hydrolysis of the epoxides. Inspired by this, we prepared three POM-intercalated LDHs of $\mathrm{Zn}_{3} \mathrm{Al}-\mathrm{Zn} \mathrm{n}_{5} \mathrm{WO}, \mathrm{Zn}_{3} \mathrm{Al}-\mathrm{Zn}_{2} \mathrm{Mn}_{3} \mathrm{WO}$ and $\mathrm{Zn}_{3} \mathrm{Al}-\mathrm{Zn}_{2} \mathrm{Fe}_{3} \mathrm{WO}$ and 
studied their efficiency in the oximation of aromatic aldehydes in the presence of $\mathrm{H}_{2} \mathrm{O}_{2}$ in the absence of organic solvents [7]. Interestingly, utilization of the POM-intercalated catalyst for the oximation reaction of aromatic aldehydes revealed an improvement of the selectivity compared to the homogeneous catalytic system promoted by the aqueous POMs solution. The enhanced selectivity of the desirable products is attibuted to the cooperative effect between the components of the composite materials which modulate the inherent acidity of the POM clusters, which would otherwise promote the production of amides and nitriles via acid-catalyzed side reactions. The reaction pathway is illustrated in Figure 12.

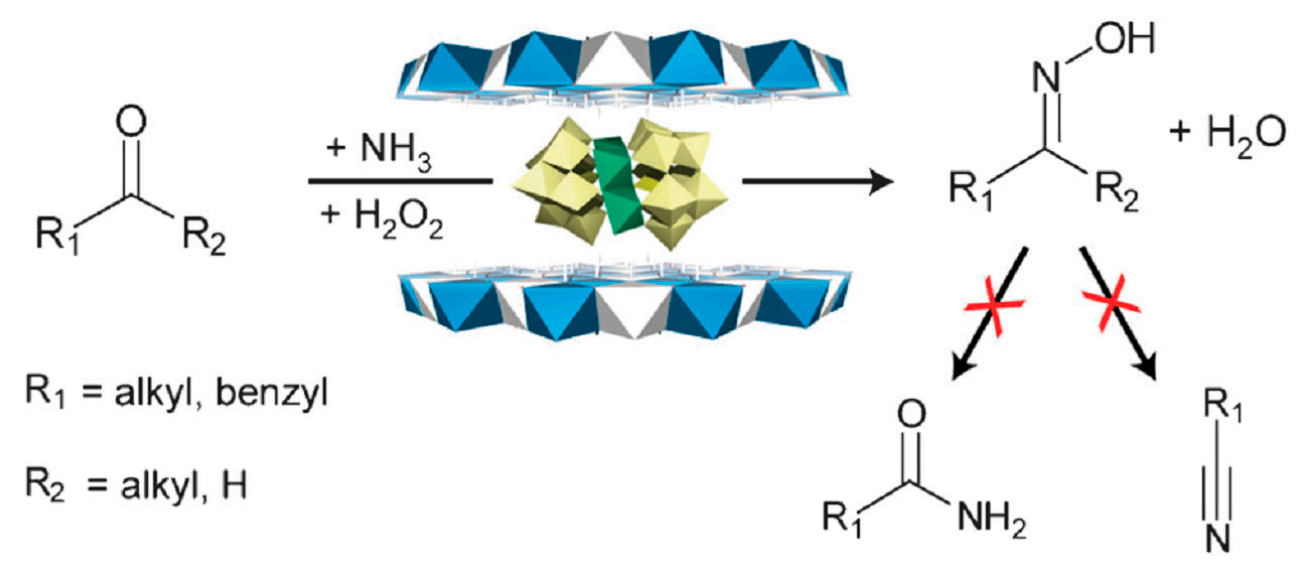

Figure 12. Schematic of the synergistic effect of LDH-POM catalysts for promotion oximation of aromatic aldehydes [7]. Adapted from Ref. [12], Copyright 2014, Elsevier.

The cyanosilylation of aldehydes or ketones with trialkylsilyl cyanides is an example of important reactions in industry and synthetic chemistry. The cyanosilylation promotes the formation of new C-C bonds while protecting the hydroxo functional groups [74]. Moreover, the corresponding cyanohydrins products can be transformed into a variety of building blocks, such as $\beta$-amino alcohols, $\alpha$-hydroxy ketones and $\alpha$-hydroxy acids [75], which are widely applied in synthetic chemistry. Hence, many efforts have been dedicated to investigating the cyanosilylation reaction, where both acid [76] and base catalysts $[77,78]$ were utilized to promote the cyanosilylation reaction. Therefore, fabrication of the acid-base synergistic catalyst is a promising method to develop systems that could catalyze efficiently the cyanosilylation reaction. Recently, we prepared a series of $\mathrm{Mg}_{3} \mathrm{Al}-\mathrm{LnW}_{10}$ ( $\mathrm{Ln}=\mathrm{Dy}$, $\mathrm{Eu}, \mathrm{Tb}$ ) catalysts employing the exfoliation assembly method [44]. The temperature-programmed desorption of carbon dioxide $\left(\mathrm{CO}_{2}\right.$-TPD) and ammonia $\left(\mathrm{NH}_{3}-\mathrm{TPD}\right)$ demonstrated that the resulting POM-intercalated catalysts possess both acid and basic properties. As such, the $\mathrm{Mg}_{3} \mathrm{Al}-\mathrm{EuW}_{10}$ catalyst has been successfully employed in the catalysis of cyanosilylation of various aldehydes or ketones with excellent catalytic activity under solvent-free conditions. The $\mathrm{Mg}_{3} \mathrm{Al}-\mathrm{EuW}_{10}$ can be easily separated and reused for 10 times without obvious decrease of the catalytic performance; the composition and structure of $\mathrm{Mg}_{3} \mathrm{Al}-\mathrm{EuW}_{10}$ catalyst remained stable during the catalytic cycle. In addition, the $\mathrm{Mg}_{3} \mathrm{Al}-\mathrm{EuW}_{10}$ catalyzed cyanosilylation of hexanal and benzaldehyde revealed the highest TON of 119906 and 119950, respectively.

\section{Conclusions-Perspectives}

In summary, over recent decades, several different methods have been developed for the design of POM-LDH-intercalated composites by various research groups in an effort to overcome the inherent challenges associated with the process: (i) Some POMs are hydrolytically unstable under weakly acidic to basic $\mathrm{pH}$ environment leading to formation of impurities during the intercalation reactions; (ii) the intercalation process is closely related to the charge density, size, and geometry of the POM clusters; (iii) leaching of the metal ions ( $\mathrm{M}^{\mathrm{II}}$ or $\mathrm{M}^{\mathrm{III}}$ ) from the host layer can occur under neutral to slightly 
acidic environments. In contrast to the traditional methods, we recently developed the host layer modification and exfoliation assembly methods demonstrating the advantages of these approaches and effectively tackling the aforementioned limitations to some extent. These two new methods not only modulate the host-guest interactions and overcome its spatial and geometrical restrictions of POMs (such as the intercalation of Keggin species, $\left[\mathrm{PW}_{12} \mathrm{O}_{40}\right]^{3-}$, of low negative charge) but also prevent the leaching of $\mathrm{Mg}^{\mathrm{II}} / \mathrm{Al}^{\mathrm{III}}$ cations during the intercalation process promoting the formation of the POM-LDH composite without co-formation of the impurity phase. The POM-LDH composites have been widely utilized successfully in different catalytic processes, such as oxidation catalysis, acid catalysis and acid-base synergistic catalysis etc. The as-prepared POM-LDH composites show superior catalytic performance comparing to the relevant performance of its parent components. This is due to synergistic effects arising from intermolecular interactions such as electrostatic and network hydrogen bonds, which prevent agglomeration and enhance the overall performance. The active components are uniformly dispersed in the 2D confined space defined by the LDH layers. Additionally, the design of the robust confined space in combination with the intermolecular interactions induces further stability to the system, prevents leaching of the POM species into the reaction mixture and increases the catalyst's selectivity. Further investigation and expansion of the family of POM-LDH composite materials will offer great opportunities for the development of economical and versatile methods for designing specific structural features that could drive reactions towards the desirable direction and modulate the electron transfer properties of the POM-LDH intercalated composite in a controlled manner. Finally, the exploration of alternative design approaches will pave the way for the construction of POM-LDHs composites that exhibit new chemical and physical properties, emergence of functionalities as well as broaden the catalytic applications of this family of novel materials.

Acknowledgments: This research was supported by the National Basic Research Program of China (973 program, 2014CB932104), National Nature Science Foundation of China (U1407127, U1507102, 21521005, 21625101), International Joint Graduate-Training Program of Beijing University of Chemical Technology, and Fundamental Research Funds for the Central Universities (ZY1709). H.N.M. acknowledges the financial support from the University of Glasgow.

Author Contributions: Y.-F.S., and H.N.M. conceived and designed the structure of the review article. T.F.L. conducted the literature search and collected the relevant material. T.F.L., Y.-F.S. and H.N.M co-write and revised the article.

Conflicts of Interest: The authors declare no conflict of interest.

\section{References}

1. Fan, G.L.; Li, F.; Evans, D.G.; Duan, X. Catalytic applications of layered double hydroxides: Recent advances and perspectives. Chem. Soc. Rev. 2014, 43, 7040-7066. [CrossRef] [PubMed]

2. Wang, Q.; O'Hare, D. Recent Advances in the Synthesis and Application of Layered Double Hydroxide (LDH) Nanosheets. Chem. Rev. 2012, 112, 4124-4155. [CrossRef] [PubMed]

3. Sideris, P.J.; Nielsen, U.G.; Gan, Z.; Grey, C.P. Mg/Al Ordering in Layered Double Hydroxides Revealed by Multinuclear NMR Spectroscopy. Science 2008, 321, 113-117. [CrossRef] [PubMed]

4. Yin, H.J.; Tang, Z.Y. Ultrathin two-dimensional layered metal hydroxides: An emerging platform for advanced catalysis, energy conversion and storage. Chem. Soc. Rev. 2016, 45, 4873-4891. [CrossRef] [PubMed]

5. Williams, G.R.; Khan, A.I.; O'Hare, D. Mechanistic and Kinetic Studies of Guest Ion Intercalation into Layered Double Hydroxides Using Time-resolved, in situ X-ray Powder Diffraction. Struct. Bond. 2006, 119, 161-192.

6. Evans, D.G.; Slade, R.C.T. Structural Aspects of Layered Double Hydroxides. Struct. Bond. 2006, 119, 1-87.

7. Zhao, S.; Xu, J.H.; Wei, M.; Song, Y.-F. Synergistic catalysis by polyoxometalate-intercalated layered double hydroxides: Oximation of aromatic aldehydes with large enhancement of selectivity. Green Chem. 2011, 13, 384-389. [CrossRef]

8. Guo, X.X.; Zhang, F.Z.; Xu, S.L.; Evans, D.G.; Duan, X. Preparation of layered double hydroxide films with different orientations on the opposite sides of a glass substrate by in situ hydrothermal crystallization. Chem. Commun. 2009, 28, 6836-6838. [CrossRef] [PubMed] 
9. Evans, D.G.; Duan, X. Preparation of layered double hydroxides and their applications as additives in polymers, as precursors to magnetic materials and in biology and medicine. Chem. Commun. 2006, 485-496. [CrossRef] [PubMed]

10. Xu, Z.P.; Stevenson, G.S.; Lu, C.Q.; Lu, G.Q.; Bartlett, P.F.; Gray, P.P. Stable Suspension of Layered Double Hydroxide Nanoparticles in Aqueous Solution. J. Am. Chem. Soc. 2006, 128, 36-37. [CrossRef] [PubMed]

11. Rives, V.; Ulibarri, M.A. Layered double hydroxides (LDH) intercalated with metal coordination compounds and oxometalates. Coord. Chem. Rev. 1999, 181, 61-120. [CrossRef]

12. Omwoma, S.; Chen, W.; Tsunashima, R.; Song, Y.-F. Recent advances on polyoxometalates intercalated layered double hydroxides: From synthetic approaches to functional material applications. Coord. Chem. Rev. 2014, 258-259, 58-71. [CrossRef]

13. Duan, X.; Zhang, F.Z. Intercalation Assembly and Functional Materials; Chemical Industry Press: Beijing, China, 2007.

14. Theiss, F.L.; Ayoko, G.A.; Frost, R.L. Synthesis of layered double hydroxides containing $\mathrm{Mg}^{\mathrm{II}}, \mathrm{Zn}^{\mathrm{II}}, \mathrm{Ca}^{\mathrm{II}}$ and $\mathrm{Al}^{\mathrm{III}}$ layer cations by co-precipitation methods-A review. Appl. Surf. Sci. 2016, 383, 200-213. [CrossRef]

15. Li, K.W.; Kumada, N.; Yonesaki, Y.; Takei, T.; Kinomura, N.; Wang, H.; Wang, C. The pH effects on the formation of $\mathrm{Ni} / \mathrm{Al}$ nitrate form layered double hydroxides (LDHs) by chemical precipitation and hydrothermal method. Mater. Chem. Phys. 2010, 121, 223-229. [CrossRef]

16. Inayat, A.; Klumpp, M.; Schwieger, W. The urea method for the direct synthesis of ZnAl layered double hydroxides with nitrate as the interlayer anion. Appl. Clay Sci. 2011, 51, 452-459. [CrossRef]

17. Qu, J.; Zhang, Q.W.; Li, X.W.; He, X.M.; Song, S.X. Mechanochemical approaches to synthesize layered double hydroxides: A review. Appl. Clay Sci. 2016, 119, 185-192. [CrossRef]

18. Zubaira, M.; Daud, M.; McKay, G.; Shehzad, F.; Al-Harthi, M.A. Recent progress in layered double hydroxides (LDH)-containing hybrids as adsorbents for water remediation. Appl. Clay Sci. 2017, 143, 279-292. [CrossRef]

19. Bi, X.; Zhang, H.; Dou, L.G. Layered Double Hydroxide-Based Nanocarriers for Drug Delivery. Pharmaceutics 2014, 6, 298-332. [CrossRef] [PubMed]

20. Feng, Y.J.; Li, D.Q.; Wang, Y.; Evans, D.G.; Duan, X. Synthesis and characterization of a UV absorbentintercalated Zn-Al layered double hydroxide. Polym. Degrad. Stab. 2006, 91, 789-794. [CrossRef]

21. Wang, X.; Sumboja, A.; Lin, M.F.; Yan, J.; Lee, P.S. Enhancing electrochemical reaction sites in nickel-cobalt layered double hydroxides on zinc tin oxide nanowires: A hybrid material for an asymmetric supercapacitor device. Nanoscale 2012, 4, 7266-7272. [CrossRef] [PubMed]

22. Chen, Y.; Song, Y.-F. Highly Selective and Efficient Removal of $\mathrm{Cr}(\mathrm{VI})$ and $\mathrm{Cu}(\mathrm{II})$ by the Chromotropic Acid-Intercalated Zn-Al Layered Double Hydroxides. Ind. Eng. Chem. Res. 2013, 52, 4436-4442. [CrossRef]

23. Kuroda, Y.; Miyamoto, Y.; Hibino, M.; Yamaguchi, K.; Mizuno, N. Tripodal Ligand-Stabilized Layered Double Hydroxide Nanoparticles with Highly Exchangeable $\mathrm{CO}_{3}{ }^{2-}$. Chem. Mater. 2013, 25, 2291-2296. [CrossRef]

24. Kuroda, Y.; Koichi, T.; Muramatsu, K.; Yamaguchi, K.; Mizuno, N.; Shimojima, A.; Wada, H.; Kuroda, K. Direct Synthesis of Highly Designable Hybrid Metal Hydroxide Nanosheets by Using Tripodal Ligands as One-Size-Fits-All Modifiers. Chem. Eur. J. 2017, 23, 5023-5032. [CrossRef] [PubMed]

25. Oka, Y.; Kuroda, Y.; Matsuno, T.; Kamata, K.; Wada, H.; Shimojima, A.; Kuroda, K. Preparation of Mesoporous Basic Oxides through Assembly of Monodispersed Mg-Al Layered Double Hydroxide Nanoparticles. Chem. Eur. J. 2017, 23, 9362-9368. [CrossRef] [PubMed]

26. Pinnavaia, T.J.; Chibwe, M.; Constantino, V.R.L.; Yun, S.K. Organic chemical conversions catalyzed by intercalated layered double hydroxides (LDHs). Appl. Clay Sci. 1995, 10, 117-129. [CrossRef]

27. Tatsumi, T.; Yamamoto, K.; Tajima, H.; Tominaga, H.-O. Shape selective epoxidation of alkenes catalysed by polyoxometalate-intercalated hydrotalcite. Chem. Lett. 1992, 21, 815-818. [CrossRef]

28. Song, Y.-F.; Tsunashima, R. Recent advances on polyoxometalate-based molecular and composite materials. Chem. Soc. Rev. 2012, 41, 7384-7402. [CrossRef] [PubMed]

29. Miras, H.N.; Vilà-Nadal, L.; Cronin, L. Polyoxometalate based open-frameworks (POMOFs). Chem. Soc. Rev. 2014, 43, 5679-5699. [CrossRef] [PubMed]

30. Wang, S.S.; Yang, G.Y. Recent advances in polyoxometalate-catalyzed reactions. Chem. Rev. 2015, 115, 4893-4962. [CrossRef] [PubMed]

31. Zhou, Y.; Guo, Z.J.; Hou, W.; Wang, Q.; Wang, J. Polyoxometalate-based phase transfer catalysis for liquid-solid organic reactions: A review. Catal. Sci. Technol. 2015, 5, 4324-4335. [CrossRef] 
32. Yamaguchi, K.; Yoshida, C.; Uchida, S.; Mizuno, N. Peroxotungstate immobilized on ionic liquid-modified silica as a heterogeneous epoxidation catalyst with hydrogen peroxide. J. Am. Chem. Soc. 2005, 127, 530-531. [CrossRef] [PubMed]

33. Inumaru, K.; Ishihara, T.; Kamiya, Y.; Okuhara, T.; Yamanaka, S. Water-tolerant, highly active solid acid catalysts composed of the Keggin-type polyoxometalate $\mathrm{H}_{3} \mathrm{PW}_{12} \mathrm{O}_{40}$ เmmobilized in hydrophobic nanospaces of organomodified mesoporous silica. Angew. Chem. Int. Ed. 2007, 46, 7625-7628. [CrossRef] [PubMed]

34. Kwon, T.; Tsigdinos, G.A.; Pinnavaia, T.J. Pillaring of Layered Double Hydroxides (LDH's) by Polyoxometalate Anions. J. Am. Chem. Soc. 1988, 110, 3653-3654. [CrossRef]

35. Yun, S.K.; Pinnavaia, T.J. Layered Double Hydroxides Intercalated by Polyoxometalate Anions with Keggin $\left(\alpha-\mathrm{H}_{2} \mathrm{~W}_{12} \mathrm{O}_{40}{ }^{6-}\right)$, Dawson $\left(\alpha-\mathrm{P}_{2} \mathrm{~W}_{18} \mathrm{O}_{62}{ }^{6-}\right)$, and Finke $\left(\mathrm{Co}_{4}\left(\mathrm{H}_{2} \mathrm{O}\right)_{2}\left(\mathrm{PW}_{9} \mathrm{O}_{34}\right)_{2}{ }^{10-}\right)$ Structures. Inorg. Chem. 1996, 35, 6853-6860. [CrossRef] [PubMed]

36. Liu, K.; Yao, Z.X.; Song, Y.-F. Polyoxometalates Hosted in Layered Double Hydroxides: Highly Enhanced Catalytic Activity and Selectivity in Sulfoxidation of Sulfides. Ind. Eng. Chem. Res. 2015, 54, 9133-9141. [CrossRef]

37. Liu, P.; Wang, C.H.; Li, C. Epoxidation of allylic alcohols on self-assembled polyoxometalates hosted in layered double hydroxides with aqueous $\mathrm{H}_{2} \mathrm{O}_{2}$ as oxidant. J. Catal. 2009, 262, 159-168. [CrossRef]

38. Narita, E.; Kaviratna, P.D.; Pinnavaia, T.J. Direct synthesis of a polyoxometallate-pillared layered double hydroxide by coprecipitation. J. Chem. Soc. Chem. Commun. 1993, 60-62. [CrossRef]

39. Jana, S.K.; Kubota, Y.; Takashi, T. Cobalt-substituted polyoxometalate pillared hydrotalcite: Synthesis and catalysis in liquid-phase oxidation of cyclohexanol with molecular oxygen. J. Catal. 2008, 255, 40-47. [CrossRef]

40. Li, T.F.; Wang, Z.L.; Xu, Y.Q.; Wei, C.; Song, Y.-F. Recent progress in polyoxometalate-intercalated layered double hydroxides composite materials. Sci. China Chem. 2017, 47, 451-464. [CrossRef]

41. Chen, Y.; Yan, D.P.; Song, Y.-F. Tris(hydroxymethyl)aminomethane modified layered double hydroxides greatly facilitate polyoxometalate intercalation. Dalton Trans. 2014, 43, 14570-14576. [CrossRef] [PubMed]

42. Cho, S.; Kwag, J.; Jeong, S.; Baek, Y.; Kim, S. Highly Fluorescent and Stable Quantum Dot-Polymer-Layered Double Hydroxide Composites. Chem. Mater. 2013, 25, 1071-1077. [CrossRef]

43. Gunjakar, J.L.; Kim, T.W.; Kim, H.N.; Kim, I.Y.; Hwang, S.-J. Mesoporous Layer-by-Layer Ordered Nanohybrids of Layered Double Hydroxide and Layered Metal Oxide: Highly Active Visible Light Photocatalysts with Improved Chemical Stability. J. Am. Soc. Chem. 2011, 133, 14998-15007. [CrossRef] [PubMed]

44. Jia, Y.Q.; Zhao, S.; Song, Y.-F. The application of spontaneous flocculation for the preparation of lanthanide-containing polyoxometalates intercalated layered double hydroxides: Highly efficient heterogeneous catalysts for cyanosilylation. Appl. Catal. A Gen. 2014, 487, 172-180. [CrossRef]

45. Kuo, W.G. Decolorizing dye wastewater with Fenton's reagent. Water Res. 1992, 26, 881-886. [CrossRef]

46. Chen, Y.; Yao, Z.X.; Miras, H.N.; Song, Y.-F. Modular Polyoxometalate-Layered Double Hydroxide Composites as Efficient Oxidative Catalysts. Chem. Eur. J. 2015, 21, 10812-10820. [CrossRef] [PubMed]

47. Jiang, B.; Yang, H.W.; Zhang, L.H.; Zhang, R.Y.; Sun, Y.L.; Huang, Y. Efficient oxidative desulfurization of diesel fuel using amide-based ionic liquids. Chem. Eng. J. 2016, 283, 89-96. [CrossRef]

48. Xu, Y.Q.; Xuan, W.M.; Zhang, M.M.; Miras, H.N.; Song, Y.-F. A multicomponent assembly approach for the design of deep desulfurization heterogeneous catalysts. Dalton Trans. 2016, 45, 19511-19518. [CrossRef] [PubMed]

49. Xu, X.D.; Moulijn, J.A.; Ito, E.; Wagemans, R.; Makkee, M. Deep Desulfurization of Fossil Fuels by Air in the Absence of a Catalyst. ChemSusChem 2008, 1, 817-819. [CrossRef] [PubMed]

50. Shannon, M.S.; Irvin, A.C.; Liu, H.Q.; Moon, J.D.; Hindman, M.S.; Turner, C.H.; Bara, J.E. Chemical and Physical Absorption of $\mathrm{SO}_{2}$ by N-Functionalized Imidazoles: Experimental Results and Molecular-level Insight. Ind. Eng. Chem. Res. 2015, 54, 462-471. [CrossRef]

51. Kaernbach, W.; Kisielow, W.; Warzecha, L.; Miga, K.; Klecan, R. Influence of petroleum nitrogen compounds on hydrodesulphurization. Fuel 1990, 69, 221-224. [CrossRef]

52. Macaud, M.; Sévignon, M.; Favre-Réguillon, A.; Lemaire, M. Novel Methodology toward Deep Desulfurization of Diesel Feed Based on the Selective Elimination of Nitrogen Compounds. Ind. Eng. Chem. Res. 2004, 43, 7843-7849. [CrossRef] 
53. Yao, Z.Y.; Miras, H.N.; Song, Y.-F. Efficient concurrent removal of sulfur and nitrogen contents from complex oil mixtures by using polyoxometalate-based composite materials. Inorg. Chem. Front. 2016, 3, 1007-1013. [CrossRef]

54. Bamoharram, F.F.; Heravi, M.M.; Roshani, M.; Tavakoli, N. N-oxidation of pyridine carboxylic acids using hydrogen peroxide catalyzed by a green heteropolyacid catalyst: Preyssler's anion, $\left[\mathrm{NaP}_{5} \mathrm{~W}_{30} \mathrm{O}_{110}\right]^{14-}$. J. Mol. Catal. A 2006, 252, 219-225. [CrossRef]

55. Malkov, A.V.; Bell, M.; Castelluzzo, F.; Kočovský, P. METHOX: A New Pyridine N-Oxide Organocatalyst for the Asymmetric Allylation of Aldehydes with Allyltrichlorosilanes. Org. Lett. 2005, 7, 3219-3222. [CrossRef] [PubMed]

56. Liu, K.; Yao, Z.X.; Miras, H.N.; Song, Y.-F. Facile Immobilization of a Lewis Acid Polyoxometalate onto Layered Double Hydroxides for Highly Efficient N-Oxidation of Pyridine-Based Derivatives and Denitrogenation. ChemCatChem 2015, 7, 3903-3910. [CrossRef]

57. Corma, A.; Ródenas, T.; Sabater, M.J. Monoalkylations with alcohols by a cascade reaction on bifunctional solid catalysts: Reaction kinetics and mechanism. J. Catal. 2011, 279, 319-327. [CrossRef]

58. Liu, P.; Li, C.; Hensen, E.J. Efficient Tandem Synthesis of Methyl Esters and Imines by Using Versatile Hydrotalcite-Supported Gold Nanoparticles. Chem. Eur. J. 2012, 18, 12122-12129. [CrossRef] [PubMed]

59. Zhu, F.X.; Wang, W.; Li, H.X. Water-Medium and Solvent-Free Organic Reactions over a Bifunctional Catalyst with Au Nanoparticles Covalently Bonded to $\mathrm{HS} / \mathrm{SO}_{3} \mathrm{H}$ Functionalized Periodic Mesoporous Organosilica. J. Am. Chem. Soc. 2011, 133, 11632-11640. [CrossRef] [PubMed]

60. Felpin, F.X.; Fouquet, E. Heterogeneous Multifunctional Catalysts for Tandem Processes: An Approach toward Sustainability. ChemSusChem 2008, 1, 718-724. [CrossRef] [PubMed]

61. Elhamifar, D.; Kazempoor, S.; Karimi, B. Amine-functionalized ionic liquid-based mesoporous organosilica as a highly efficient nanocatalyst for the Knoevenagel condensation. Catal. Sci. Technol. 2016, 6, 4318-4326. [CrossRef]

62. Zhang, L.N.; Wang, H.; Shen, W.Z.; Qin, Z.F.; Wang, J.G.; Fan, W.B. Controlled synthesis of graphitic carbon nitride and its catalytic properties in Knoevenagel condensations. J. Catal. 2016, 344, 293-302. [CrossRef]

63. Zhao, S.; Chen, Y.; Song, Y.-F. Tri-lacunary polyoxometalates of $\mathrm{Na}_{8} \mathrm{H}\left[\mathrm{PW}_{9} \mathrm{O}_{34}\right]$ as heterogeneous Lewis base catalysts for Knoevenagel condensation, cyanosilylation and the synthesis of benzoxazole derivatives. Appl. Catal. A Gen. 2014, 475, 140-146. [CrossRef]

64. Ezugwu, C.I.; Mousavi, B.; Asraf, M.A.; Luo, Z.X.; Verpoort, F. Post-synthetic modified MOF for Sonogashira cross-coupling and Knoevenagel condensation reactions. J. Catal. 2016, 344, 445-454. [CrossRef]

65. Liu, K.; Xu, Y.Q.; Yao, Z.Y.; Miras, H.N.; Song, Y.-F. Polyoxometalate-Intercalated Layered Double Hydroxides as Efficient and Recyclable Bifunctional Catalysts for Cascade Reactions. ChemCatChem 2016, 8, 929-937. [CrossRef]

66. Li, T.F.; Wang, Z.L.; Chen, W.; Miras, H.N.; Song, Y.-F. Rational Design of a Polyoxometalate Intercalated Layered Double Hydroxide: Highly Efficient Catalytic Epoxidation of Allylic Alcohols under Mild and Solvent-Free Conditions. Chem. Eur. J. 2017, 23, 1069-1077. [CrossRef] [PubMed]

67. Xu, X.D.; Henninger, T.; Abbanat, D.; Bush, K.; Foleno, B.; Hilliard, J.; Macielag, M. Synthesis and antibacterial activity of C2-fluoro, C6-carbamate ketolides, and their C9-oximes. Bioorg. Med. Chem. Lett. 2005, 15, 883-887. [CrossRef] [PubMed]

68. Jain, N.; Kumar, A.; Chauhan, S.M.S. Metalloporphyrin and heteropoly acid catalyzed oxidation of $\mathrm{C}=\mathrm{NOH}$ bonds in an ionic liquid: Biomimetic models of nitric oxide synthase. Tetrahedron Lett. 2005, 46, $2599-2602$. [CrossRef]

69. Bars, J.L.; Dakka, J.; Sheldon, R.A. Ammoximation of cyclohexanone and hydroxyaromatic ketones over titanium molecular sieves. Appl. Catal. A Gen. 1996, 136, 69-80. [CrossRef]

70. Song, F.; Liu, Y.M.; Wu, H.H.; He, M.Y.; Wu, P.; Tatsumi, T. A novel titanosilicate with MWW structure: Highly effective liquid-phase ammoximation of cyclohexanone. J. Catal. 2006, 237, 359-367. [CrossRef]

71. Li, Z.H.; Chen, R.Z.; Xing, W.H.; Jin, W.Q.; Xu, N.P. Continuous Acetone Ammoximation over TS-1 in a Tubular Membrane Reactor. Ind. Eng. Chem. Res. 2010, 49, 6309-6316. [CrossRef]

72. Sloboda-Rozner, D.; Neumann, R. Aqueous biphasic catalysis with polyoxometalates: Oximation of ketones and aldehydes with aqueous ammonia and hydrogen peroxide. Green Chem. 2006, 8, 679-681. [CrossRef] 
73. Liu, P.; Wang, H.; Feng, Z.C.; Ying, P.L.; Li, C. Direct immobilization of self-assembled polyoxometalate catalyst in layered double hydroxide for heterogeneous epoxidation of olefins. J. Catal. 2008, 256, 345-348. [CrossRef]

74. Brunel, J.M.; Holmes, I.P. Chemically Catalyzed Asymmetric Cyanohydrin Syntheses. Angew. Chem. Int. Ed. 2004, 43, 2752-2778. [CrossRef] [PubMed]

75. Sreekanth, P.; Kim, S.-W.; Hyeon, T.; Kim, B.M. A Novel Mesoporous Silica-Supported Lewis Acid Catalyst for C-C Bond Formation Reactions in Water. Adv. Synth. Catal. 2003, 345, 936-938. [CrossRef]

76. Procopio, A.; Das, G.; Nardi, M.; Oliverio, M.; Pasqua, L. A Mesoporous Er ${ }^{\mathrm{III}}$-MCM-41 Catalyst for the Cyanosilylation of Aldehydes and Ketones under Solvent-free Conditions. ChemSusChem 2008, 1, 916-919. [CrossRef] [PubMed]

77. Song, J.J.; Gallou, F.; Reeves, J.T.; Tan, Z.L.; Yee, N.K.; Senanayake, C.H. Activation of TMSCN by N-Heterocyclic Carbenes for Facile Cyanosilylation of Carbonyl Compounds. J. Org. Chem. 2006, 71, 1273-1276. [CrossRef] [PubMed]

78. Denmark, S.E.; Chung, W.J. Lewis Base Catalyzed Addition of Trimethylsilyl Cyanide to Aldehydes. J. Org. Chem. 2006, 71, 4002-4005. [CrossRef] [PubMed]

(C) 2017 by the authors. Licensee MDPI, Basel, Switzerland. This article is an open access article distributed under the terms and conditions of the Creative Commons Attribution (CC BY) license (http://creativecommons.org/licenses/by/4.0/). 